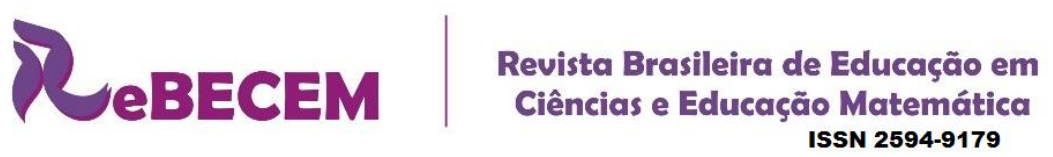

DOI: https://doi.org/10.33238/ReBECEM.2020.v.4.n.3.24150

\title{
RESENHA DO LIVRO: HABERMAS E AS PROFESSORAS E PROFESSORES DE MATEMÁTICA: VISLUMBRANDO OÁSIS DE DEISE APARECIDA PERALTA
}

Flavio Augusto Leite Taveira ${ }^{1}$

Habermas e as Professoras e Professores de Matemática: vislumbrando oásis nasce como fruto de temática de pesquisa desenvolvida pela autora desde seu doutoramento junto ao Programa de Pós-Graduação em Educação para Ciência da Universidade Estadual Paulista Júlio de Mesquita Filho (UNESP), campus de Bauru, focando a formação de professoras e professores de matemática no Brasil em contexto de reformas curriculares e de avaliação em larga escala.

A autora é licenciada em Matemática pela UNESP - campus de São José do Rio Preto e Mestra em Psicologia do Desenvolvimento e da Aprendizagem pela mesma instituição em que realizou o doutoramento. Atualmente é professora lotada junto ao Departamento de Matemática da UNESP - campus de Ilha Solteira, sendo uma das líderes do Grupo de Pesquisa em Currículo: Estudos, Práticas e Avaliação (GEPAC) e docente permanente do Programa Multidisciplinar Interunidades de Pós-Graduação em Ensino e Processos Formativos também da UNESP, atuando na linha de Educação Matemática e de Tecnologias, Diversidades e Culturas.

Como considerações iniciais, destaca-se que a obra expressa a análise seguindo os pressupostos que embasam seu referencial teórico: a Teoria da Ação Comunicativa de Habermas e a possibilidade de interação formativa (continuada) de professoras e professores de matemática, durante o exercício da profissão, em contextos de implantação de currículos e de avaliação em larga escala. O exemplo mais latente presente nas descrições e análises do livro refere-se ao processo de implementação do Currículo do Estado de São Paulo e de desenvolvimento do Sistema de Avaliação do Rendimento Escolar do Estado de São Paulo (SARESP).

\footnotetext{
${ }^{1}$ Licenciatura em Matemática. Universidade Estadual Paulista Júlio de Mesquita Filho - UNESP. Ilha Solteira, São Paulo, Brasil. Bolsista do Programa Instituicional de Bolsas de Iniciação Científica (Pibic). E-mail: flavio.taveira@unesp.br
} 


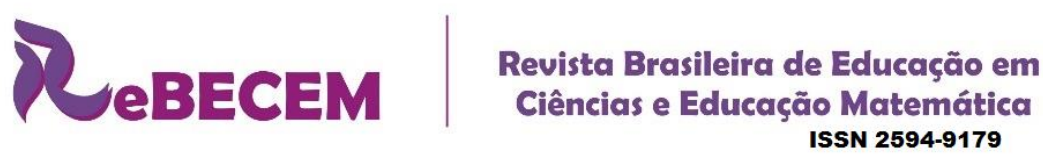

DOI: https://doi.org/10.33238/ReBECEM.2020.v.4.n.3.24150

A obra defende que o ideário habermasiano proposto na Teoria da Ação Comunicativa considera a sociedade moderna compreendida por dois sistemas sociais que se complementam na formação da realidade social: o Sistema e o Mundo da Vida. A racionalidade que subjaz às ações e interação no Sistema é a racionalidade Instrumental, que contemporâneos de Habermas já criticavam como sendo uma racionalidade que orienta ações voltadas às práticas de dominação e de convencimento do outro em benefício próprio. Alternativamente, a racionalidade Comunicativa proposta por Habermas se contrapõe à Instrumental, buscando sempre consenso e clareza nos atos de fala em processo de comunicação, visando com que aqueles que se comunicam possam se entender (Esclarecimento).

$\mathrm{Na}$ seção de caráter introdutório do livro apresentado nessa resenha são apresentadas três inquietações: (1) a relevância dos termos Competência e Habilidade no Currículo de Matemática não parecem proporcional aos espaços de esclarecimentos sobre a definição quanto a estes termos; (2) a formação de professoras para efetuar análises entre os indicadores de avaliação de um conteúdo de matemática e o desempenho dos alunos; (3) a possibilidade de conceber diretrizes curriculares oficiais com finalidade Emancipatória. A partir dessas inquetações são expostos os objetivos da pesquisa relatada no livro, a saber: discutir as evidências que demonstram a compreensão das professoras e professores de Matemática a respeito dos conceitos de competências e habilidades; verificar se as estratégias e condições de orientação empregada pelas matrizes de referência cumprem o papel de auxiliar o professor a planejar sua prática; ampliar a visibilidade sobre formas de elaboração de orientações didáticas para práticas docentes; discutir orientações didáticas expressas no Currículo do Estado de São Paulo no âmbito da Teoria do Agir Comunicativo; defender que um modelo crítico de interação e formação de professores é possível e apresenta vantagens em tornar o professor protagonista em processos de implantação curricular.

No primeiro capítulo, a autora apresenta o referencial teórico que embasa sua investigação: a Teoria da Ação Comunicativa de Jürgen Habermas. Esse referencial fundamenta o que a autora chamou de Modelo Comunicativo de Interação. Ela descreve uma possibilidade de interação com professoras e professores de matemática, defendendo um potencial formativo a partir dos pressupostos que embasam o Agir Comunicativo. Nesse capítulo é apresentado o histórico da Teoria Crítica da Sociedadde e seus principais pensadores, localizando Habermas nesse conjunto de filósofos da 
DOI: https://doi.org/10.33238/ReBECEM.2020.v.4.n.3.24150

Escola de Frankfurt. Assim, a autora retoma o contexto em que tal teoria se apresenta, no conjunto dos pensadores de Frankfurt, sendo uma das justificativas o de superar o pessimismo que os antecessores de Habermas - Theodor Adorno e Max Horkheimer tinham em relação ao projeto social de Modernidade.

Ainda nessa seção, há descrição das principais ideias do Agir Comunicativo, elucidando expressões como Ação, Discurso, Pretensão de Validez e com destaque duas expressões: o Sistema e o Mundo da Vida. Tal destaque é realizado tendo em vista que para o filósofo, o Mundo da Vida é o pano de fundo do Agir Comunicativo e por tal, deve ser um dos meios de resistência aos imperativos sistêmicos. A tentativa de penetrar a racionalidade que consubtancia as ações no interior do Sistema (que se denomina racionalidade Instrumental) no Mundo da Vida é entendida por Habermas como colonização e se constitui em um importante fator para análises discursivas.

A partir das considerações teóricas e filosóficas realizadas, o segundo capítulo traz uma discussão acerca de uma interpretação do nosso atual modelo de educação sob a ótica do Agir Comunicativo, propondo uma outra racionalidade na formação de professores, a racionalidade Comunicativa. Uma interessante e pertinente constatação feita pela autora é que a formação de professores e a prática docente tem se pautado na racionalidade Instrumental, entendendo que o mercado - um dos componentes do constructo filosófico do Sistema na teoria de Habermas - tem assumido a finalidade na e da formação de professores.

Ainda no segundo capítulo, além de apresentar uma gama de autores que já se valeram do mesmo referencial teórico para pensar questões em Educação e Ensino, a autora sinaliza dois que lhe foram determinantes para defender a ideia de que é possível um outro paradigma de formação de professoras e professores, que se paute na ampla participação em cenários de reformas curriculares no estado de São Paulo. O primeiro, Eldon Henrique Mühl, auxiliou a autora a compreender a possibilidade de (re) construção e (re) significação da teoria e prática docente de acordo com o Agir Comunicativo; a segunda, Lizete Maria Orquiza de Carvalho, revelou a possibilidade de desenvolvimento de uma cultura de argumentação entre professores com objetivo Emancipatório.

No capítulo que segue se faz uma comparação entre a música "Caviar", interpretada por Zeca Pagodinho, e o fato de que o termo "Competências" se faz presente no cotidiano da rede de docentes do Estado de São Paulo, mas que os mesmos 
DOI: https://doi.org/10.33238/ReBECEM.2020.v.4.n.3.24150

não o reconhecem em suas ações, mas também não o contestam. São reunidas contribuições acerca do termo supracitado e dá início a uma discussão sobre o quanto tal termo tem impactado nas formulações curriculares, na organização educacional no Estado de São Paulo e na prática docente. Entende-se, em suma, que a compreensão de tal termo tem estado no limiar entre o senso comum e científico, assumindo compreensões muito subjetivas, podendo admitir diversas definições. É defendida a urgência de uma formação de professores adequada e que saiba analisar as correspondências entre as condições de trabalho, avaliação e desempenho, seja quais forem os objetivos preconizados pelos materiais curriculares que impactam em tal prática profissional.

No quarto capítulo, o caminho da pesquisa que deu origem ao livro passa pelos aspectos éticos, filosóficos e de constituição do percurso metodológico de investigação, levantamento bibliográfico e levantamento de campo, descrevendo participantes e procedimentos.

Já no quinto capítulo, as marcas e os traços da investigação são discutidos. Como resultado do levantamento bibliográfico, a autora relata e identifica movimentos de reformas curriculares que ocorreram em esfera federal e em esfera estadual paulista. A primeira reforma descrita é a reforma Francisco Campos que, como característica principal, ratificou legalmente a junção Artimética, Álgebra e Geometria em Matemática nos currículos escolares do ensino básico. A segunda reforma descrita é a Reforma Capanema que ficou caracterizada pelas Leis Orgânicas de Ensino. A terceira A Portaria Ministerial de 1951, descrita como uma terceira reforma, estabeleceu os "Programas Mínimos" de ensino. Na sequência, são apresentadas a primeira Lei de Diretrizes e Bases da Educação Nacional (LDBEN), publicada em 1961; a LDBEN de 1971, sucedida pelos Guias Curriculares do Estado de São Paulo de 1973; as Propostas Curriculares do Estado de São Paulo de 1978 e 1986; a LDBEN de 1996 e os Parâmetros Curriculares Nacionais; finalizando com as Orientações Curriculares para o Ensino Médio e o Currículo do Estado de São Paulo. Já como resultado do levantamento de campo, a autora descreve a interação com as professoras participantes da pesquisa, nomeadamente ANA e BIA, caracterizando os discursos, as práticas docentes pré-interação formativa, o processo de interação, a prática docente pósinteração e finaliza com uma avaliação desse processo. Após todo o processo, a partir do relato das professoras, a autora notou que a forma como se relacionou com as 
DOI: https://doi.org/10.33238/ReBECEM.2020.v.4.n.3.24150

professoras participantes da pesquisa refletiu e impactou nas práticas adotadas pelas mesmas na sala de aula: oferecendo espaços para que os alunos pudessem expor o que pensavam e por consequência levantarem hipóteses sobre o conteúdo a ser estudado, por exemplo. Oportunizar espaços de falas e propiciar o diálogo livre de coerções e assimetrias constitui uma das grandes proposições do referencial teórico utilizado.

No sexto capítulo, a autora realiza uma análise das reformas curriculares ocorridas no Estado de São Paulo à luz da teoria que lhe embasa, caracterizando em tais reformas uma racionalidade estratégica e concluindo a presença de uma ação instrumental - constituída na base de uma racionalidade Instrumental - na proposição e implantação de tais reformas. Ainda descreve e reflete sobre a interação com professores de Matemática inspirada na Teoria da Ação Comunicativa e avalia a possibilidade de uma Modelo Comunicativo de Interação, que possibilitou às professoras refletirem sobre as pretensões presentes no currículo vigente e sobre as próprias práticas pedagógicas.

Por fim, a título de conclusão, a autora defende um Modelo Comunicativo de Interação como possibilidade na formação continuada de professores de Matemática, pautada numa racionalidade alternativa à instrumental, vislumbrando "uma utopia possível”. Explicita as suas compreensões acerca de três pontos que a inquietaram inicialmente na realização da pesquisa. Neste sentido, a autora entende que as proposições presentes e defendidas no Currículo de Matemática do Estado de São Paulo não realizam o esforço de serem compreendidas (1); que o professor é capaz de analisar a relação que estabelece entre o que prega as proposições curriculares e o desempenho dos alunos (2) e; que é possível conceber proposições curriculares que admitam finalidade Emancipatória pregando pela participação do professorado na implantação de tais proposições (3). Em seu último parágrafo, a autora reafirma a necessidade da defesa de um espaço de utopia em educação, pois acredita que se a utopia se esgota, não teremos para onde "caminhar".

Sobre a relevância desta obra, entendo que a mesma se assenta num forte referencial que além de teórico pode ser metodológico e que não tem sido utilizado, principalmente, no campo da Educação Matemática. Nesse sentido, além de nos trazer uma nova possibilidade de análise de discursos e processos de interação, a autora realiza um resgate das reformas educacionais ocorridas no Brasil e no Estado de São Paulo desde o século passado. Ao propor um modelo de interação com professores de 


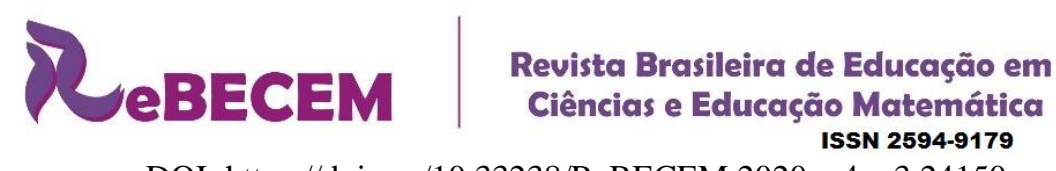

DOI: https://doi.org/10.33238/ReBECEM.2020.v.4.n.3.24150

Matemática com vistas ao Esclarecimento, contesta um jogo de intencionalidades que, como evidenciadas, estão presentes nas reformas curriculares. Intencionalidades essas que escondem vontades pessoais e políticas e colocam em risco - ao direcionar as necessidades de pequenos grupos, que por meio do capital e do poder, exercem influências nas políticas públicas e nas ações educacionais do país - uma das principais tarefas da Educação Matemática: formar (pela Matemática) para o Esclarecimento e para o efetivo exercício da cidadania.

\section{Referências}

PERALTA, D. A. Habermas e as Professoras e Professores de Matemática: vislumbrando oásis. 1. Ed. Curitiba: Appris, 2019.

Recebido em: 29 de fevereiro de 2020

Aceito em: 21 de julho de 2020 